\section{Are welders more at risk of respiratory infections?}

\author{
David Coggon, Keith T Palmer
}

Welding of metals generates a complex mix of noxious gases and fumes, ${ }^{1}$ and has been linked with various respiratory diseases including metal fume fever, ${ }^{2}$ asthma, ${ }^{3}$ $\mathrm{COPD}^{4}$ and possibly bronchial carcinoma. ${ }^{1}{ }^{2}$ In addition, there is now strong and consistent epidemiological evidence that welders are at increased risk of infectious, lobar pneumonia. Originally detected in national analyses of occupational mortality, ${ }^{5}$ the hazard was confirmed by a large case-control study of men admitted to hospitals in the English West Midlands with community-acquired pneumonia, ${ }^{6}$ and is supported by findings from more recent epidemiological investigations in the $\mathrm{UK}^{78}$ and other countries. ${ }^{9-11}$

The elevation of risk is associated specifically with recent exposure, ${ }^{6}$ and is not apparent in former welders after normal retirement age, ${ }^{5}{ }^{7}$ suggesting that it reflects a reversible increase in susceptibility to infection. Moreover, it extends to other occupations such as furnacemen and moulders in foundries, who are exposed to metal fume but not to welding gases..$^{5}$ It is demonstrable in men who work with ferrous metals, ${ }^{6} 12$ but the involvement of other metals cannot be ruled out. Resolution of this uncertainty with adequate statistical power is a challenge because lobar pneumonia is uncommon, and relatively few workers are exposed to fume exclusively from nonferrous metals. In Britain, larger numbers of workers were employed in metal manufacture historically, and before 1960 statistics were published on mortality among men employed specifically in non-ferrous foundries. However, data on pneumonia are inconsistent. Brass moulders and nonferrous foundry workers had significantly elevated death rates in 1930-1932, but no excess during 1949-1953. ${ }^{12}$

Also uncertain is the range of infectious agents to which susceptibility is increased. Streptococcus pneumoniae, which is the bacterium that most commonly causes

MRC Lifecourse Epidemiology Unit, University of Southampton, Southampton, UK

Correspondence to Professor D Coggon, Medical Research Council Lifecourse Epidemiology Unit, University of Southampton, Southampton General Hospital, Southampton S016 6YD, UK; dnc@mrc.soton.ac.uk lobar pneumonia, is clearly affected, but data on mortality by occupation suggest an increased risk also of non-bronchial pneumonia caused by other microorganisms. ${ }^{56}$

Various mechanisms have been proposed that might explain the hazard. One theory is that inhaled iron acts as a nutrient for microorganisms, promoting their growth. ${ }^{12}$ This would accord with the observations that propensity to infections is increased in patients with sickle cell disease who release free iron into the blood during haemolytic crises, and in patients with haemochromatosis who absorb dietary iron excessively. ${ }^{12}$ Moreover, the reversibility of the increase in susceptibility could be explained if following cessation of exposure, free iron in the lung over time became bound to carrier proteins, making it inaccessible to pathogens. This hypothesis would accommodate an effect on a range of microorganisms, but could not account for a hazard from non-ferrous metals.

Another possibility is that metal fume impairs immune responses in the lung. The oxidative stress that is generated by transition metals on the surface of ultrafine particles in such fume would be expected to stimulate an acute inflammatory response. However, analysis of blood and induced sputum from a group of long-term welders showed no difference in inflammatory markers from unexposed controls, ${ }^{13}$ prompting the hypothesis that long-term inhalation of welding fume might blunt the normal acute response to inhaled particulate. Such an effect could occur from various metals and affect various microorganisms.

A third hypothesis is that metal fume enhances the binding of the pneumococcus to lung tissue. Some strains of pneumococci adhere firmly to and invade bronchial epithelium by co-opting host proteins, including the platelet-activating factor receptor (PAFR), which becomes stimulated by a bacterial phospholipid that mimics the natural ligand platelet-activating factor. Mild steel welding fumes have been found in vitro and in mouse models to promote PAFR protein expression, pneumococcal adhesion and cell invasion. ${ }^{14} \mathrm{~A}$ mechanism of this sort would not necessarily be limited to ferrous fume, but would apply specifically to pneumococcal infections.
Against this background, a new paper published in this edition of Thorax suggests that welders also have higher rates of upper respiratory infections. ${ }^{15}$ The findings come from two parallel lines of investigation, both focusing on employees at a shipyard in the Middle East. In a cross-sectional survey, welders reported a significantly higher prevalence of respiratory symptoms than other manual labourers in winter months (OR 2.31). And in a longitudinal analysis of consultations at the staff medical centre, welders consulted for respiratory infections (mainly of the upper respiratory tract) more frequently than other manual labourers. Again, the difference was greater in winter (adjusted incidence rate ratio 1.47) than in summer (1.33), but it was significant in both seasons.

The study had a number of limitations, which the authors acknowledge. In the cross-sectional survey, symptoms might not have been a reliable marker of respiratory infections; the data on medical consultations relied on the accuracy of diagnostic coding, which is unlikely to have been entirely consistent and accurate; and no information was available on smoking habits.

Another concern is the possibility of confounding by differences in propensity to report or consult for symptoms, particularly as workers' consultation behaviour differed according to their country of origin, and a relatively high proportion of welders came from Bangladesh. However, risk estimates were adjusted for nationality as well as season and exposure time.

Furthermore, the differential effect in winter as compared with summer was not a prior hypothesis. The authors note that in the United Arab Emirates, seasonal influenza peaks in the winter months. However, they do not present data on consultation for influenza specifically.

In view of these limitations, and the absence of increased sickness absence for respiratory disease in an earlier study of welders, ${ }^{16}$ there is a need for confirmation by independent research in other populations, before an increased risk of upper respiratory infections among welders can be considered established. If there is indeed a hazard, it would not of itself be a major concern-a potentially increased risk of upper respiratory infections is accepted, for example, in occupations entailing contact with infants and children. However, it could provide further important clues to the mechanisms underlying the hazard of lobar pneumonia, with the possibility of a shared pathogenesis that was not specific to the pneumococcus. A better understanding of the mechanisms is 


\section{Editorial}

needed because the rarity of lobar pneumonia makes it difficult to establish exposure-response relationships directly by epidemiological investigations. With knowledge of mechanism, it might be possible to develop biomarkers for the increase in susceptibility to infection, which could then be related to the levels of exposure. The information thus generated would then guide limits on exposure to control the risk.

Contributors The commentary was jointly written by the two authors.

Funding Medical Research Council.

Competing interests None declared.

Provenance and peer review Commissioned; externally peer reviewed.

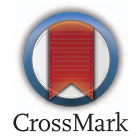

To cite Coggon D, Palmer KT. Thorax 2016;71:581582.

Published Online First 21 April 2016

\section{SLinked}

- http://dx.doi.org/10.1136/thoraxjnl-2015-207912

Thorax 2016;71:581-582.

doi:10.1136/thoraxinl-2016-208464

\section{REFERENCES}

1 International Agency for Research on Cancer. IARC Monographs on the evaluation of carcinogenic risks to humans. Volume 49 Chromium, nickel and welding. Lyon: IARC, 1990. http://monographs.iarc.fr/ ENG/Monographs/vol49/

2 Antonini JM, Lewis AB, Roberts JR, et al. Pulmonary effects of welding fumes: review of worker and experimental animal studies. Am I Indust Med 2003:43:350-60.

3 Baur X. A compendium of causative agents of occupational asthma. J Occup Med Toxicol 2013;8:15.

4 Rushton L. Occupational causes of chronic obstructive pulmonary disease. Rev Environ Health 2007:22:195-212.

5 Coggon D, Inskip H, Winter $P$, et al. Lobar pneumonia: an occupational disease in welders. Lancet 1994;344:41-3.

6 Palmer KT, Poole J, Ayres JG, et al. Exposure to metal fume and infectious pneumonia. Am $J$ Epidemiol 2003;157:227-33.

7 Palmer KT, Cullinan P, Rice S, et al. Mortality from infectious pneumonia in metal workers: a comparison with deaths from asthma in occupations exposed to respiratory sensitisers. Thorax 2009;64:983-6.

8 Coggon D, Harris EC, Cox V, et al. Pneumococcal vaccination for welders. Thorax 2015;70:198-9.

9 Wergeland E, Iversen BG. Deaths from pneumonia after welding. Scand I Work Environ Health. 2001;27:353.

10 Wong A, Marrie TJ, Garg S, et al. Welders are at increased risk for invasive pneumococcal disease. Int J Infect Dis. 2010;14:e796-9.

11 Torén K, Qvarfordt I, Bergdahl IA, et al. Increased mortality from infectious pneumonia after occupational exposure to inorganic dust, metal fumes and chemicals. Thorax 2011;66:992-6.

12 Palmer K, Coggon D. Does occupational exposure to iron promote infection? Occup Environ Med 1997;54:529-34.

13 Palmer KT, McNeill Love RM, Poole JR, et al. Inflammatory responses to the occupational inhalation of metal fume. Eur Respir J 2006;27:366-73.

14 Suri R, Periselneris J, Lanone S, et al. Exposure to welding fumes and lower airway infection with Streptococcus pneumoniae. J Allergy Clin Immunol 2016;137: 527-34.

15 Marongiu A, Hasan O, Ali A, et al. Are welders more at risk of respiratory infections? Findings from a cross-sectional survey and analysis of medical records in shipyard workers: the WELSHIP project. Thorax 2016;71:601-6.

16 McMillan GHG, Molyneux MK. The health of welders in naval dockyards: the work situation and sickness absence patterns. J Soc Occup Med 1981;31:43-60. 